\title{
REFLEXÕES PARA ALÉM DOS 500 ANOS DA REFORMA PROTESTANTE ${ }^{1}$
}

\section{Suzana Terezinha Matiello²}

\begin{abstract}
Resenha de: WOLFF, E.; ZEFERINO, J.; COLET, R.; ANDRADE, R. (Orgs.). Ecclesia semper reformanda: reflexões para além dos 500 anos da Reforma Protestante. Curitiba: PUCPRESS, 2019. 208p. ISBN 978-85-54945-59-6. Distribuição gratuita ${ }^{3}$
\end{abstract}

A obra está situada historicamente em contexto de profundo significado: 2017, ano que o cristianismo recordou os 500 anos da Reforma iniciada por Martinho Lutero, primeiro centenário comemorado em espírito ecumênico e com grandes repercussões no mundo inteiro ${ }^{4}$, suscitando simpósios, congressos, encontros com características diferentes para continuar a caminhada ecumênica com nova consciência crítica, valorizando os aspectos que unem os cristãos católicos e protestantes no anúncio do Reino de Deus, já presente na dinâmica de Mateus 18,20.

Neste espírito a presente obra foi redigida por especialistas em diversas áreas de conhecimento proporcionando uma leitura hermenêutica dos fatos acontecidos no ocidente com o evento da Reforma Protestante. Trata-se, primeiramente de uma obra qualificada, escrita e organizada por membros do Grupo de Pesquisa em Teologia, Ecumenismo e diálogo Inter-religioso, da PUCPR em parceria com pesquisadores de outras instituições como a Faculdades EST, UMESP, UNIVILLE, PUC do Chile, UNICAMP e Northwestern University (EUA).

São um conjunto de oito capítulos acrescido do prefácio e da apresentação da obra, com dados finais sobre os autores e autoras católicos, luteranos e metodistas que abordam aspectos importantes da teologia de Lutero. Já no prefácio ${ }^{5}$ da obra realizado por Walter Altmann e na apresentação de Elias Wolff', se capta o cunho de relações ecumênicas traçadas por longas décadas de amizade e trabalhos realizados em espírito de fraternidade e respeito

1 Submetido em: 18.04.2020. Aceito em: 13.08.2020

2 Graduação em Filosofia pela UNIOESTE, PR. Graduada em Ciências Religiosas pelo Instituto Superior de Ciências Religiosas, ISCRSL e em Teologia pela Pontificia Facoltá Teologica dell'Italia Meredionale, PFTIM, ambas da Itália. Mestrado em Licenza in teologia morale sociale pela Pontificia Facoltà Teologica dell'Italia Meridionale, PFTIM, Itália. Doutoranda em Teologia na Pontifícia Universidade Católica do Paraná - PUC, PR. Contato: Susimatiello@gmail.com

3 Doravante não incluiremos a referência da coletânea na indicação dos capítulos.

4 Sobre o espírito ecumênico e global desta celebração ver: PONTIFíCIO CONSELHO PARA A PROMOÇÃO DA UNIDADE DOS CRISTÃOS; FEDERAÇÃO LUTERANA MUNDIAL. Do Conflito à Comunhão: Comemoração conjunta católico-luterana da Reforma em 2017. Relatório da Comissão Luterana - Católico-Romana para a Unidade. Brasília: Edição conjunta Edições CNBB e Editora Sinodal, 2015.

5 ALTMANN, W. Prefácio. p. 4-11.

6 WOLFF, E. Apresentação. p. 12-17.

Protestantismo em Revista | São Leopoldo | v. 46, n. 01 | p. 193-196| Jan./jun. 2020

Disponível em: <http://periodicos.est.edu.br/index.php/nepp> 
entre as duas tradições cristãs. No conjunto da obra se nota coesão metodológica e clareza na exposição das diversas temáticas.

A primeira contribuição ${ }^{7}$, de Martin Timóteo Dietz e Jefferson Zeferino, é uma abordagem focada em três momentos acerca da relação entre o Espírito Santo e a Igreja, analisando a interpretação do terceiro artigo do Credo em Lutero e em Barth. Conclui-se que "as pneumatologias de Lutero e Barth, em relações eclesiológicas e antropológicas, pensam o humano em comunhão enquanto proliferador do amor com o qual de antemão teria sido amado"$^{\prime 8}$.

A segunda contribuição ${ }^{9}$ tem como título: A comunidade de fé como modelo para o Estado secular a partir da concepção política de Martinho Lutero, o autor do texto, Euler Renato Westphal, aborda a base teológica do Estado Laico, analisa "a fundamentação da ideia de Reino de Deus e Reino do mundo em Lutero" ${ }^{10}$. Westphal questiona sobre as raízes da separação entre Estado e Igreja e as implicações e limites que esse processo acarreta; em diálogo com Habermas, citando Vattimo, evidencia o pensamento de Lutero sobre a questão.

A terceira contribuição ${ }^{11}$ da teóloga luterana Wanda Deifelt, analisa a sexualidade e corporeidade na teologia de Lutero e as controvérsias com o pensamento da Igreja Católica romana no período medieval. A rica abordagem da teóloga luterana sublinha que a contribuição de Lutero "não foi apenas o desenvolvimento de uma compreensão única do ser humano, mas sim, como esse ser humano está situado no todo da criação" ${ }^{12}$.

A quarta contribuição ${ }^{13}$ de Thiago Vieira Nogueira e Marcial Maçaneiro traz como título: Maria, o Espírito e a Igreja: Uma Análise Pneumatológico-Ecclesiológica da Teologia Mariana de Lutero. A abordagem perpassa o pensamento e a devoção mariana no contexto medieval - entra na teologia mariana do reformador Luterano, esclarece o seu pensamento resgatando o fundamento bíblico no qual a Mãe de Cristo, segundo as Sagradas Escrituras, é a mulher "moldada por Deus, conduzida pelo Espírito Santo e ornada de virtudes, as quais a Igreja é convidada a imitar, sobretudo na geração de Cristo nos fiéis"14.

Na quinta contribuição ${ }^{15}$, o historiador e professor Rui Luis Rodrigues, destaca a posição do humanista Erasmo de Rotterdam em relação a não adesão à Reforma de Lutero ${ }^{16}$, e indaga o modo "como Erasmo se posicionou diante dos movimentos religiosos que eclodiram na Europa após o protesto de Lutero"17. O autor evidencia a "expectativa

DIETZ, M.; ZEFERINO, J. O Espírito Santo e a Igreja: a interpretação do terceiro artigo do Credo em Lutero e Barth. p. 18-35.

8 DIETZ; ZEFERINO, 2019, p. 34.

9 WESTPHAL, E. A comunidade de fé como modelo para o estado secular a partir da concepção política de Martinho Lutero. p.36-55.

10 WESTPHAL, 2019, p. 43.

11 DEIFELT, W. Sexualidade e corporeidade na teologia de Martim Lutero. p. 56-77.

12 DEIFELT, 2019, p.62.

13 NOGUEIRA, T.; MAÇANEIRO, M. Maria, o Espírito e a Igreja: uma análise pneumatológico-eclesiológica da teologia mariana de Lutero. p. 78-112.

14 NOGUEIRA; MAÇANEIRO, 2019, p. 79-80.

15 RODRIGUES, R. Erasmo e os reformadores. p. 114-138.

16 RODRIGUES, 2019, p. 117.

RODRIGUES, 2019, p.120.

Protestantismo em Revista | São Leopoldo | v. 46, n. 01 | p. 193-196| Jan./jun. 2020

Disponível em: <http://periodicos.est.edu.br/index.php/nepp> 
erasmiana" por uma reforma "que não deveria criar uma nova igreja, mas configurá-la, no presente, de acordo com os moldes fornecidos pela Patrística"18.

Na sexta contribuição ${ }^{19}$ o autor, Rodrigo Polanco, analisa a eclesiologia do Concílio Vaticano II, sublinhando o processo de uma Igreja que está sempre em desenvolvimento, em "constante renovação, uma renovação criativa" ${ }^{20}$; uma Igreja que procura "ser sempre fiel ao seu mistério fundante que é ser presença de Cristo que caminha junto ao gênero humano" 21 .

A sétima contribuição ${ }^{22}$, primeiramente aborda a relação de Lutero com a mística cristã, em um segundo momento as Sagradas Escrituras são apresentadas como centro da espiritualidade da Reforma e, para finalizar, os autores, Elias Wolff e Rodrigo de Andrade, identificam elementos de solução ecumênica, identificando a "espiritualidade ecumênica como força unitiva, conjuntiva, comunicativa" ${ }^{23}$.

A oitava contribuição ${ }^{24}$ do metodista Helmut Renders, expõe e analisa a Teologia da cruz na cultura visual evangélica brasileira do século $X X$, evidencia descobertas e desafios, e destaca como a teologia da cruz "continua sendo um símbolo - chave da fé cristã para a leitura da contemporaneidade e para encontrar pistas a fim de garantir a sobrevivência de toda a criação, inclusive da humanidade" ${ }^{\prime 25}$, sua interessante investigação destaca a influência da "cultura evangélica visual, em tratados e cartazes"26.

Com base nos trabalhos que compõem a obra se verifica que os autores fizeram recortes claros e bem apresentados com significativas bases bibliográficas e ricas notas de rodapé, fornecendo ao(à) leitor(a) ulteriores possibilidades de avançar no conhecimento da trajetória da Igreja cristã. Portanto, em uma primeira instancia a obra é direcionada ao âmbito acadêmico, mas a sua linguagem precisa, clara e investigativa é acessível para um público que deseja conhecer aspectos importantes da Reforma, nesta perspectiva podem se beneficiar do texto sejam as pastorais, movimentos eclesiais e centros ecumênicos.

As contribuições presentes na obra, são sinal de esperança no relacionamento e conhecimento recíproco entre os cristãos das diferentes tradições, no desafio constante de superação das múltiplas divisões existentes na cristandade ${ }^{27}$, portanto continuar o caminho do diálogo é um imperativo como indicado no documento Do Conflito à Comunhão: Comemoração conjunta Católico-Luterana da Reforma em 2017. Por isso, recomendamos a obra resenhada tanto para acadêmicos como para o conhecimento e formação dos cristãos das diferentes tradições e para todas as pessoas interessadas e empenhadas no compromisso ecumênico.

20 POLANCO, 2019, p. 154.

21 POLANCO, 2019, p. 154.

22 WOLFF, E.; ANDRADE, R. Sola Scriptura: a boa nova da espiritualidade da Reforma. p. 156-169.

23 WOLFF; ANDRADE, 2019, p. 168.

24 RENDERS, H. A teologia da cruz na cultura visual evangélica brasileira do século 20: descobertas e desafios. p. 170-197.

25 RENDERS, 2019, p. 172.

26 RENDERS, 2019, p. 173.

27 ALTMANN, 2019, p. 6.

Protestantismo em Revista | São Leopoldo | v. 46, n. 01 | p. 193-196| Jan./jun. 2020

Disponível em: <http://periodicos.est.edu.br/index.php/nepp> 


\section{Referências}

ALTMANN, W. Prefácio. In: WOLFF, E. et al. (Org.). Ecclesia semper reformanda: reflexões para além dos 500 anos da Reforma Protestante. Curitiba: PUCPRESS, 2019, p. 4-11

DEIFELT, W. Sexualidade e corporeidade na teologia de Martim Lutero. In: WOLFF, E. et al. (Org.). Ecclesia semper reformanda: reflexões para além dos 500 anos da Reforma Protestante. Curitiba: PUCPRESS, 2019, p. 56-77.

DIETZ, M.; ZEFERINO, J. O Espírito Santo e a Igreja: a interpretação do terceiro artigo do Credo em Lutero e Barth. In: WOLFF, E. et al. (Org.). Ecclesia semper reformanda: reflexões para além dos 500 anos da Reforma Protestante. Curitiba: PUCPRESS, 2019, p. 18-35

NOGUEIRA, T.; MAÇANEIRO, M. Maria, o Espírito e a Igreja: uma análise pneumatológicoeclesiológica da teologia mariana de Lutero. In: WOLFF, E. et al. (Org.). Ecclesia semper reformanda: reflexões para além dos 500 anos da Reforma Protestante. Curitiba: PUCPRESS, 2019, p. 78-112

POLANCO, R. Reforma como acontecimiento permanente de la iglesia, según el Concilio Vaticano II. In: WOLFF, E. et al. (Org.). Ecclesia semper reformanda: reflexões para além dos 500 anos da Reforma Protestante. Curitiba: PUCPRESS, 2019, p.140-155

PONTIFÍCIO CONSELHO PARA A PROMOÇÃO DA UNIDADE DOS CRISTÃOS; FEDERAÇÃO LUTERANA MUNDIAL. Do Conflito à Comunhão: Comemoração conjunta católico-luterana da Reforma em 2017. Relatório da Comissão Luterana - Católico-Romana para a Unidade. Brasília: Edição conjunta Edições CNBB e Editora Sinodal, 2015.

RENDERS, H. A teologia da cruz na cultura visual evangélica brasileira do século 20: descobertas e desafios. In: WOLFF, E. et al. (Org.). Ecclesia semper reformanda: reflexões para além dos 500 anos da Reforma Protestante. Curitiba: PUCPRESS, 2019, p. 170-197.

RODRIGUES, R. Erasmo e os reformadores. In: WOLFF, E. et al. (Org.). Ecclesia semper reformanda: reflexões para além dos 500 anos da Reforma Protestante. Curitiba: PUCPRESS, 2019, p. 114-138.

WESTPHAL, E. A comunidade de fé como modelo para o estado secular a partir da concepção política de Martinho Lutero. In: WOLFF, E. et al. (Org.). Ecclesia semper reformanda: reflexões para além dos 500 anos da Reforma Protestante. Curitiba: PUCPRESS, 2019, p.36-55.

WOLFF, E. Apresentação. In: WOLFF, E. et al. (Org.). Ecclesia semper reformanda: reflexões para além dos 500 anos da Reforma Protestante. Curitiba: PUCPRESS, 2019, p. 12-17

WOLFF, E.; ANDRADE, R. Sola Scriptura: a boa nova da espiritualidade da Reforma. In: WOLFF, E. et al. (Org.). Ecclesia semper reformanda: reflexões para além dos 500 anos da Reforma Protestante. Curitiba: PUCPRESS, 2019, p. 156-169. 